\title{
The Application of Applied Mathematics in Inventory Control
}

\section{Guannan Lin and Cuihong Zhai}

Nanchang Institute of Science \& Technology

\section{Keywords: Supply Chain; Applied Mathematics; Inventory Control; Economic Production Quantity}

\begin{abstract}
Facing the increasingly intense competition, we can adopt various policies to reduce costs and enhance the competitiveness. The company in this paper is encountered with big pressure of customer cost passthrough. How to properly organize the manufacturing, control stock, and reduce the production cost shall be primary issues. For manufacturing companies, it operates based on the demand of customer or market, they develop products, purchase materials, manufacture products in the form of goods and sell them to customers with after-sale services. Manufacturing objects start from the supplier and move toward value-added sectors which thus consist a long supply chain. This paper starts from various sectors of valued-added supply chain to establish the mathematic model describing the relation between internal supply and demand as well as the manufacturing cost based on mathematic modeling to further analyze this model and apply it in real manufacturing to solve the contradiction between supply and demand, and meanwhile reduce production costs.
\end{abstract}

\section{Introduction}

For manufacturing companies, it operates based on the demand of customer or market, they develop products, purchase materials, manufacture products in the form of goods and sell them to customers with after-sale services. Besides, the manufacturing objects start from the supplier and move toward the purchaser according to value-added sectors (original material $\rightarrow$ being processed $\rightarrow$ semi-finished products $\rightarrow$ products $\rightarrow$ commodity) and thus create a long supply chain. In addition, we have to think how to keep the fast flow of information, material and capital in the course of material valueadded movement; how to deal with the contradiction between supply and demand in various sectors of the supply chain; how to make the maximum value and profit with minimum consumption, cost and shortest manufacturing cycle.

This paper adopts widely applied mathematic means with abstract thinking, rigorous reasoning to analyze the internal relation among the value-added sectors of the supply chain with modeling, which will be helpful for manufacturing companies to quickly respond to the market demand. Meanwhile, we can realize timely production, delivery, JIT manufacturing model so as to achieve capital fast turnover, maximize the value of supply-chain, reduce the overstocking of products as well as capital takes up in the course of manufacturing so as to quickly acquire requirement information of the ultimate consumption market to help the supply chain keep up with the market changes.

\section{Targets of Supply Chain Management}

The traditional target of supply chain management is to minimize the total cost to realize the specific requirement of a certain product. The total cost includes the following items:

Original cost and other purchasing cost

Inside transportation cost

Infrastructure investment cost

Direct and indirect manufacturing cost

Direct and indirect delivery cost

Inventory cost

Transportation implementation cost

External transportation cost 
While establishing a model for specific problem design, we can consider a part of the whole supply chain and relative costs.

Companies seek for the maximum net income:

Net Income= Total Income-Total Cost. If the requirement is fixed, the total income to satisfy this requirement is fixed and then companies can maximize the net income by minimizing the total cost.

Storage Theory Model. The most simple storage theory model is economic order quantity. By balancing the purchasing cost and the warehousing cost, we can determine a optimal order quantity to minimize the total inventory cost. This model is about a single product storage management and its assumption is shown as follows:

The requirement of the product is known and the time is established

Once there should be replenishment of inventory, we have a fixed ordering cost regardless of the purchasing quantity

The products will be delivered as soon as being ordered, that is to say there is no delay time

Stockout is not allowed

The inventory cost for unit product is fixed

In economic order quantity model and other inventory models, the inventory cost for each unit product is an important parameter which is determined by the capital cost and other risk factors. Suppose $I(t)$ is the inventory in time. Figure 1 takes $I(t)$ as a function for $q$, which represents order quantity. If we use economic order quantity model we can determine the value of q so as to minimize the fixed ordering cost as well as the inventory cost to finally determine the economic order quantity, showing in the following formula:

$$
\mathrm{q}^{*}=\sqrt{(2 \mathrm{Q} / \mathrm{h})}
$$

Among which $\mathrm{K}$ refers to the fixed ordering cost

$\mathrm{D}$ refers to the total annual demand

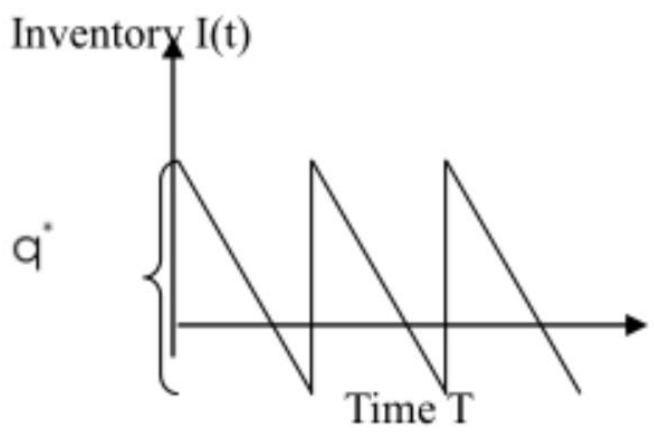

Figure 1. Fixed economic order quantity model

Optimal Inventory Assumption. According to model assumption, the optimal assumption refers to the probabilistic model which meets the economic order quantity rules. Inside the company, a small amount of inventory cost is less than breakage cost. What's more, the probability density of production line requirement can satisfy the normal distribution rule while the breakage proportion should be strictly controlled under $2 \%$ and the optimal inventory shall be safe inventory which can provide supply and demand history data, given by the following formula:

$$
S=Z \sigma_{D} \sqrt{L}
$$

$\mathrm{S}$ - Optimal inventory (safe inventory);

$\mathrm{z}$ - Safe factor controlling the breakage proportion below a certain level

$\sigma \mathrm{D}$ - Standard deviation for the difference between supply and demand based on historical data

L- Lead time length, calculated based on days and 1 day for this company

$\sigma_{D}=\sqrt{\left(X_{1}-\bar{X}\right)^{2}+\left(X_{2}-\bar{X}\right)^{2}+\left(?+\left(X_{n}-\bar{X}\right) / n\right)}$ 
In the formula:

$X_{n} \_$Supply and demand d-value per week for up-downstream unit in the supply chain

$\bar{X} \_$Mean value of the supply and demand d-value in a certain period of time

According to device settings, we can have the 278pcs/Hr maximum production capacity based on $100 \%$ yield rate and $100 \%$ utilization rate and the corresponding minimum single chip cost is $0.482 \$ / p c s$. (Note:Utilization rate refers to the proportion of effective working hour occupying total working hour, pcs refers to manufacturing quantity while $\mathrm{Hr}$ refers to hour). We can know the single chip cost in different manufacturing quantity. While adopting the EXCEL drawing function, the data distribution (production quantity-cost) is shown as follows:

Table 1

\begin{tabular}{|l|l|l|l|l|l|l|l|}
\hline $\begin{array}{l}\text { Productio } \\
\text { n quantity }\end{array}$ & 953 & 1075 & 2158 & 2393 & 2402 & 2054 & 2903 \\
\hline $\begin{array}{l}\text { Cost for } \\
\text { single } \\
\text { chip }\end{array}$ & 1.19 & 1.03 & 1.01 & 0.89 & 0.87 & 0.79 & 0.75 \\
\hline $\begin{array}{l}\text { Productio } \\
\text { n quantity }\end{array}$ & 2952 & 4521 & 6002 & 6036 & 6975 & 7340 & 8937 \\
\hline $\begin{array}{l}\text { Cost for } \\
\text { single } \\
\text { chip }\end{array}$ & 0.68 & 0.62 & 0.61 & 0.58 & 0.54 & 0.52 & 0.51 \\
\hline
\end{tabular}

\section{Conclusion}

This paper analyzes the inventory as well as the production quantity in the supply chain to come up with and solve two basic problems: in the course of implementation, this paper adopts mathematic modeling so as to fully research and collect data from the production site, which also takes advantage of the probabilistic model of EOQ to know the safe inventory that satisfy $98 \%$ production lines; besides, it uses curve-fitting and infinitesimal calculus to establish the production quantity model so as to achieve the optimal production quantity. In real application, we have to take safe inventory as the guarantee to gradually improve the production quantity to successfully apply the optimal quantity of the model into real manufacturing in order to finally improve the production capacity, yield rate and meanwhile improve the production efficiency and reduce the cost.

\section{References}

[1] Teller D M, Sheryll R, Ong L. Inventory control system: US, US 4961533 A [P]. 1990.

[2] Porras E, Dekker R. An inventory control system for spare parts at a refinery: An empirical comparison of different re-order point methods [J]. European Journal of Operational Research, 2008, 184(1):101-132.

[3] Manaster S, Mann S C. Life in the Pits: Competitive Market Making and Inventory Control. [J]. Review of Financial Studies, 1996, 9(3):953-75.

[4] Basu P, Nair S K, Basu P, et al. A decision support system for mean-variance analysis in multiperiod inventory control [J]. Decision Support Systems, 2013, 57(3):285-295.

[5] Kagami A, Homma K, Akashi K, et al. Inventory control method and system: US, US 5237496 A[P]. 1993. 
[6] Song J S, Zipkin P. Inventory Control in a Fluctuating Demand Environment [J]. Operations Research, 1993, 41(2):351-370.

[7] Song J S, Zipkin P. Inventory Control in a Fluctuating Demand Environment [J]. Operations Research, 1993, 41(2):351-370.

[8] Andersson J, Marklund J. Decentralized inventory control in a two-level distribution system [J]. European Journal of Operational Research, 2000, 127(3):483-506.

[9] Laan E V D, Wassenhove L V. Inventory Control in Hybrid Systems with Remanufacturing [J]. Management Science, 1999, 45(5):733-747.

[10]Itallie T B V, Kissileff H R. Physiology of energy intake: an inventory control model. [J]. American Journal of Clinical Nutrition, 1985, 42(5 Suppl):914-23.

[11]Laan E V D, Salomon M. Production planning and inventory control with remanufacturing and disposal [J]. European Journal of Operational Research, 1997, 102(2):264-278.

[12]Ma C C, Wang Y C, Lung I T. Computerized inventory control system: , US20080071416[P]. 2008. 